\section{Bio Core}

Exploring Scientific Community

\section{International Journal of Criminal and Forensic} Science

ISSN 2576-3563

Case Report

Open Access

\title{
Case Study of Infant Death And The Role of The Forensic Department in Kuwait
}

Nadia Al-Kandary*

Ministry of Interior, General Department of Criminal Evidence, Farwaniyah, Farwaniyah, Kuwait.

${ }^{*}$ Corresponding Author: Nadia Al-kandary, Ministry of Interior, General Department of Criminal Evidence, Farwaniyah, Farwaniyah, Kuwait, Email: pathgirl.n@gmail.com.

Citation: Nadia Al-kandary (2017), Case Study of Infant Death and the Role of the Forensic Department in Kuwait. Int J Cri \& For Sci. 1:2, 22-25.

Copyright: (C) 2017 Nadia Al-kandary. This is an open-access article distributed under the terms of the Creative Commons Attribution License, which permits unrestricted use, distribution, and reproduction in any medium, provided the original author and source are credited

Received: September 11, 2017 Accepted: December 19, 2017; Published: December 30, 2017.

\section{Introduction}

This study presents a case study of one of the cases received and the role of the Forensic Department in Kuwait along with all different diagnostic medicine specialty in solving the crime. The aim is to show the importance of Forensic tools which are used in diagnosing infant death cases beginning a complete examination in the crime scene, the background history, the result of autopsy and Forensic Laboratory work including gross pathological investigation, histology, neuropathology, microbiology, radiology and toxi-

cology. Information about the circumstances of death and the gross pathological findings at autopsy often revealed the cause of death, whether it is natural or un-natural. Figure 1 shows a flow chart of infant death case investigation in the Department of Criminal Evidence. Once occurred, the case is taken up by the police and the hospitals. They are then referred to Department of Criminal Evidence Department of Criminal Evidence where the body is examined for the cause, manner and time of death.

Keywords: Infant death, Strangulation, Asphyxia, Cardio-respiratory failure, Autopsy, Forensic Medicine Investigation

Figure-1: showing Flow chart of infant death cases to the department of criminal evidence

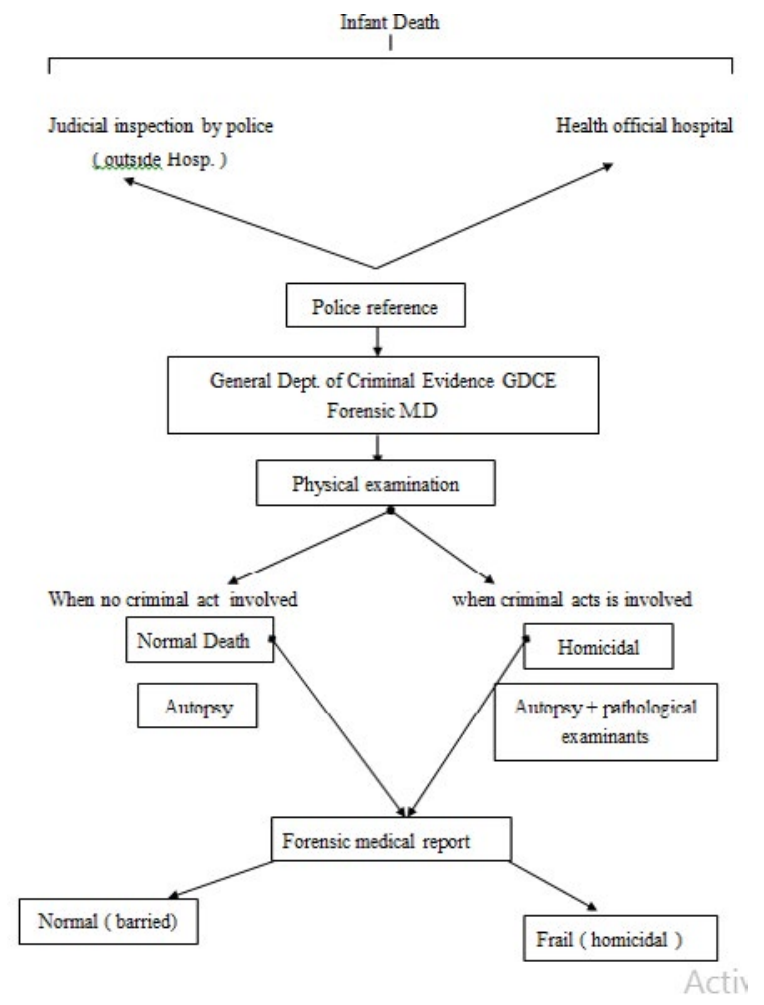


Figure 2: shows a flow chart of the protocols involving in solving a case of still birth in the department of Criminal Evidence. Once identified, the dead body is transported to the Department where a number of investigation are carried out. The dead infant is examined for the cause of death. Moreover, the umbilical cord is examined and an x-ray is taken of the body. Then external examination and a full history is taken of the case, followed by a photograph. There after an autopsy is performed to determine the cause of death.

\section{Outline of protocol for Evaluating Stillborn Infants}

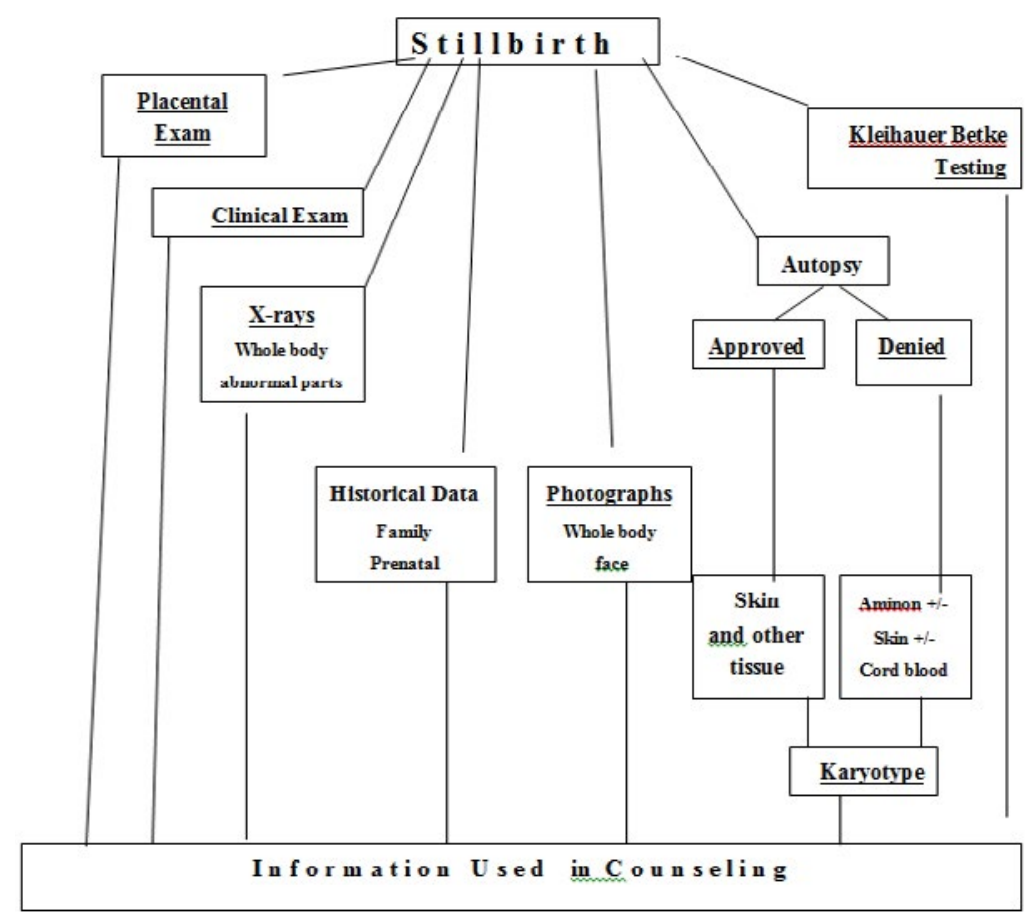

Figure 3:Flow chart showing the protocols involved in investigating a stillbirth case at the Department of Criminal Evidence

\section{Case study}

\section{Crime Scene Examination Report}

\section{Introduction}

\section{History \& circumstances}

At 12.10 pm on Monday June11 th 2007, a call was received to the Forensic Medicine Department regarding a Forensic Examination case. Following the case a crime scene team consisting of crime scene officer, a Forensic Photographer and the medico-legal ( Forensic ) doctor move instantly to the place of the crime.

Methods of Investigations

\section{A :Crime Scene Investigation}

The Crime scene team inspected Sobahia area south of Kuwait City. The crime scene area was a house owned by Kuwaiti family, the house consisted of two floors. The crime case was in ground floor exactly in a hall leading to the servant room. The team noticed a necropsy of a newly born infant dying, in prone position on the hall ground at the front of servant room. The body was rapped in a whitish towel. The team examined the servant room and the toilet. The servant was female Indonesian, 28years age and she was totally exhausted.

\section{B : Forensic Medicine Investigation}

Examination in the Crime Scene

(1) The infant was full term male, was placed on the hall ground opposite to the toilet and servant room. He was tied by a piece of pale yellow fabric on his neck

(looked a part of lady under wear ), the body was rapped in a white towel soaked with blood spots.

(2) The carpet of servant room showed dark blood clots.

(3) The toilet content was totally untidy. Complete photograph and examination of the crime scene was performed before the cadaver body was transported to the criminal evidence morgue for autopsy and looking for cause of death.

\section{Forensic Medicine Examination in the Autopsy}

1. A cadaver of naked male baby, at the beginning of post mortem rigors \& hypostasis. The crow-heal length of the baby was $49 \mathrm{~cm}$, head circumference was $31 \mathrm{~cm}$, with black hair $2 \mathrm{~cm}$ length and his nail exceeds the terminal of fingers (fingers tips), the umbilical cord stump was $16 \mathrm{~cm}$ length and still attached at the area of umbilicus (proximal end) and its distal part was irregular cutted and no ligation, its abdominal attachment shows no vital signs (reactive signs).

2. The newly born faetus showed a string ligated from anterior by a true knot and the nature of the string is formed from a feminine and wear cloth fabrics.

\section{External examination of the foetus showed}

1. Two linear abrasions around the nostrils from both sides.

2. A deep ligation mark ring shape around the whole baby neck extend form the backs sides and end in the mid of anterior surface of neck.

3. Two livear a brations, $1 \mathrm{~cm}$ each at right and left side of the neck. 


\section{Autopsy findings:}

* Head \& neck examination revealed escaped hematoma extending in left parital and temporal portions of the scalp \& however the bones of the skull were free from fractures. The anterior frontanel was almost closed. The brain showed congested blood vessels. as shown in figure 4.

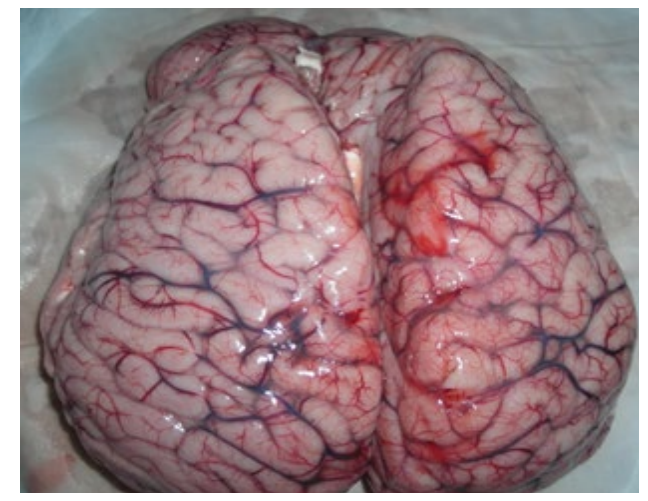

Figure 4: A photograph of the brain of a deceased infant

* Neck: Showed inimal extravastions (escaped blood) opposite the light ligature the rest of neck tissue \& laryngeal cartilage were free.

*Chest:External surface of the chest cage was free (no escaped blood). On dissection of the sternum opining of chest, both lung were voluminous \& filling the chest cavity, but the external surface of the pleura showed multiple tiny hemorrhagic spots ( peticheal hemorrhage) Tardaeu's spots. The lung tissue showed positive floating test ( inspired lung).see photo (5)

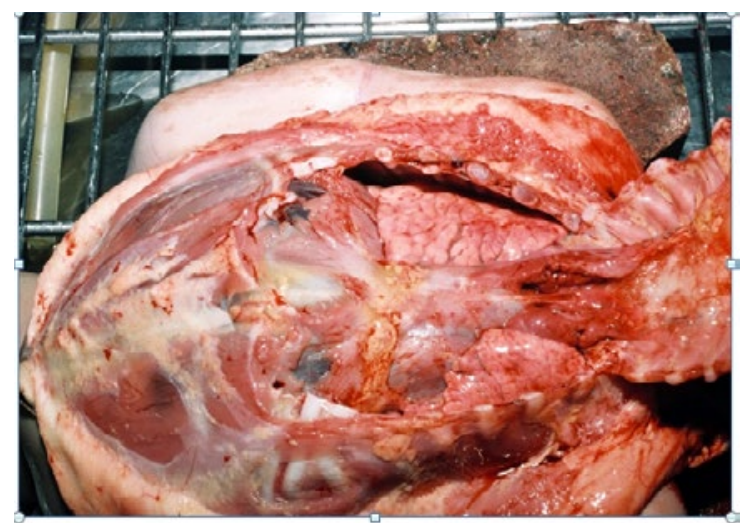

Figure 5: Illustrate breath sign from the lungs as they look in red colour

The baby heart was within normal shape \& size with only congested surface veins.

there has also been an increase in the diagnosis of cases of accidental asphyxia due to unsafe sleeping environments and of cases in which the family background and autopsy findings suggested more complex mechanisms. The change in diagnostic profile has followed the introduction of more rigorous clinical history review, death scene examination, and autopsy testing. Thus, although diagnostic outcomes have altered in this population, it is more likely the result of more interpretation of the extensive investigations that are now undertaken

\section{*Abdomen}

On dissection of abdomen, no evidence of any fluid effusion ( Ascities) or hemorrhage. The stomach showed only mucus fluid, the intestine was empty.

The lower end of femus showed ossification center $1 / 2 \mathrm{~cm}$ diam- eter.

\section{Comment}

Post mortem examination autopsy performance of new born cadaver revealed

A full term newly born baby, with evidence of criminal infanticide.

Form

1. Full inspired lung ( by gross \& microscopic )examination.

2. Presence of neck ligation strangulation (compression) mark with subcutaveous bruises.

3. Also abrasiona mark around the nose (like those of finger nails.

4. The direct cause of death was strangulation asphexia with obstruction of air passage and cardio-respiratory failure.

5. Laboratory funding had been obtained from both

Histo-pathological lab: fully inspired lung.

DNA identity for a mule baby. 


\section{Medicolegal report}

According to the DNA result the newly born male is the infant of servant.

\section{Conclusion}

From the previous outline we conclude that scientific method of forensic investigation is a time-honored approach for discovering the cause of infant death based on scientific work of forensic sciences A forensic science, assist in the investigation of infant death. The science of medicine and the principles of the law come together to enhance the collection of evidence in varies areas include forensic pathologists, forensic anthropologists, crime scene examination, radiologist with a specialty in forensics laboratories

\section{References}

1. Al Nahedh N. Infant mortality in rural Riyadh region of Saudi Arabia. Journal of the Royal Society of Health 2997, 117(2) : 1069

2. Abu-srair H; Joshua A, owa, and Amman. H (1994) Cause-specific infant mortality rate in Qatif area, Saudi Arabia; Qatif Central

\section{Note: This was a part of Master degree Thesis}

Hospital. J of Pediatrics., 102: 319-344.

3. Byard R and Krous H (1999). Suffocation, shaking or sudden infant death syndrome: Can we tell the difference? J of Pediatrics and Child Health., 35(5) 432-436.

4. Gilliland M, Levin A, Enzenauer R, Smith W, Charles, Parsons, Adams A, Lucy B, Lauridson, James R, Roche L, Obert G, Christmann L, Mian M, Jentzen J, Kenneth B, Morad Y, Alexander R, Jenny C and Wygnanski J (2007). Guidelines for postmortem protocol for ocular investigation of sudden unexplained infant death and suspected physical child abuse. Am J Forensic Med Pathol., 28(4): pp 323-329.

5. Groswasser K and Franco P (2002). Sudden infant death: arousal as survival mechanisim. J Med., 3:11-14.

6. Ishikawa T, Zhu B, Li D, Dong Z, Michie T and Hitoshi M; An autopsy case of an infant with Joubert syndrome who died unexpectedly. (2004). J Forensic Science International., 79: 132-135 